\title{
The Combination of Pain and Aggression - Two Impressive and Representative Case Reports
}

\author{
Michael Brinkers $^{1 *}$, Giselher Pfau ${ }^{1}$, Frank Meyer ${ }^{2}$, Moritz Kretzschmar ${ }^{1}$, Uwe Ebmeyer ${ }^{1}$, Thomas \\ Schilling ${ }^{1}$ \\ ${ }^{1}$ Department of Anesthesiology and Intensive Care Medicine, Otto-von-Guericke-University Magdeburg, Germany \\ ${ }^{2}$ Department of Surgery, Otto-von-Guericke-University Magdeburg, Germany
}

"Corresponding author: Michael Brinkers, Department of Anesthesiology and Intensive Care Medicine, Otto-von-Guericke-University Magdeburg, Germany, E-mail: michael.brinkers@med.ovgu.de

\begin{abstract}
Background: It is widely accepted that manifestations of pain cannot be detached from the case history, accompanying diseases, and the individual medication profile. An indirect association between pain and aggression (due to psychosis) as a cause of administration of neuroleptics has not been described yet.

Aim \& method: Here we report the connection between treatment of pain and additional medication with a neuroleptic for patients with manifest aggression and psychotic background in two impressive cases.

\section{Course \& outcome:}

Case 1: A 57-year-old male patient underwent surgery for an esophageal carcinoma. Since the second postoperative day, the patient had been given long acting morphine orally. After several days, the patient became verbally aggressive. As he was suffering from a depression, he was administered higher doses of neuroleptics. As a consequence, his pain and aggression were reduced significantly and permanently.

Case 2: A 24-year-old male patient was surgically treated for colon carcinoma. He complained about abdominal pain. Under long acting tilidine $50 \mathrm{mg}$, pain increased. Increasing dosage had no effect. However, intensity of pain (NRS 10) could only be reduced to NRS 2 by piritramide $(7.5 \mathrm{mg}$ ). Despite of the lack of psychotic disorders in the past the patient became verbally aggressive. Presuming a reactive psychosis, an administered neuroleptic reduced pain and aggression effectively and permanently.

Conclusion: If administration of painkillers does not lead to an adequate reduction of pain in the patient, and if an accompanying psychosis is present or suspected, this can manifest as aggression, an additional administration of neuroleptics needs to be considered.
\end{abstract}

Received date: February 03, 2016

Accepted date: February 26, 2016

Published date: February 27, 2016

Citation: Brinkers, M., et al The Combination of Pain and Aggression - Two Impressive and Representative Case Reports. (2016) J Anesth Surg 3(1): 102- 105

DOI: $10.15436 / 2377-1364.16 .032$

Keywords: Cancer; Pain Therapy; Psychosis; Aggression; Interdisciplinary approach.

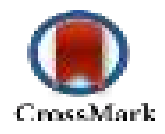

\section{Introduction}

A direct connection between pain and aggression due to psychosis as a cause to prescribe neuroleptics has not been described until now. It is usually assumed that aggression arises from the untreated pain. For that reason, pain is always treated with analgesics ${ }^{[1]}$. However, aggression with increased depressive affliction is also possible in patients without neoplasms ${ }^{[2]}$.

The concomitant medication with highly potent neuroleptic agents has been previously described but typically when aggression arises in the context of dementia ${ }^{[3]}$, intellectual disability ${ }^{[4]}$ or schizophrenia ${ }^{[5]}$. Moreover, it is necessary to differentiate be- 
tween cause and manifestation of aggression. Verbal aggression as a result of insufficient treatment with analgesics in the context of the algogenic psychic syndrome can be treated adequately with painkillers. Aggression on the basis of psychosis is practically untreatable with analgesics and requires the administration of neuroleptics ${ }^{[4]}$.

If the reduction of pain is slow or has no lasting effects and accusations from the patient itself or relatives arise, this may lead to dimensions in which a trusting collaboration is disturbed. In extreme cases, that can result in aggressive behavior of the involved parties. This situation can be triggered by an information deficit along the lines of "what is the further plan for pain therapy". We present two cases in which alternating the medication of the patient reduced the pain trigger, the aggressiveness and thereby deescalating the situation (Table 1).

\begin{tabular}{|c|c|}
\hline $\begin{array}{l}\text { Case 1: } \\
\text { Born 1957, July } \\
\text { Caucasian male, married, re- } \\
\text { tired }\end{array}$ & $\begin{array}{l}\text { Case 2: } \\
\text { Born 1990, April } \\
\text { Caucasian male, single }\end{array}$ \\
\hline $\begin{array}{l}\text { Primary Diagnosis: Esopha- } \\
\text { geal cancer (cT3cN1cMxG2), } \\
\text { neo-adjuvant radio-chemo- } \\
\text { therapy }\end{array}$ & $\begin{array}{l}\text { Primary Diagnosis: carcino- } \\
\text { ma left hemicolon; } 3 \text { surgical } \\
\text { interventions so far; last end } \\
\text { 2014: multi-visceral resec- } \\
\text { tion; currently suspected mul- } \\
\text { tiple lymphogenic metastases }\end{array}$ \\
\hline $\begin{array}{l}\text { Secondary Diagnoses: Acha- } \\
\text { lasia,biliary pancreatitis, cho- } \\
\text { lecystectomy 2014, Juli; my- } \\
\text { asthenia gravis, thymectomy } \\
\text { 1987, depression }\end{array}$ & $\begin{array}{l}\text { Secondary Diagnoses: } \\
\text { Pneumonia in both lower } \\
\text { lobes; previous one-sided ne- } \\
\text { phrectomy }\end{array}$ \\
\hline $\begin{array}{l}\text { Current medication: } \\
\text { Duloxetine } 60,1 \times 1 \\
\text { Fluoxetine } 20,2 \times 1 \\
\text { Melperone } 25 \mathrm{mg} \text {, at night } \\
\text { Pyridostigmine } 3 \times 120 \mathrm{mg} \\
\text { Quetiapine prolong } 150 \text { at } \\
\text { night (not noted during pri- } \\
\text { mary consultation) } \\
\text { Pantoprazole } 40,1 \times 1\end{array}$ & $\begin{array}{l}\text { Current medication: } \\
\text { A m p i c i } 11 \text { i n / S u l b a c t a m } \\
375 \mathrm{mg}, 2 \times 2 \\
\text { Clarithromycin 500mg, 2x1 } \\
\text { Iron Supplement } \\
\text { Pantoprazole 40, 1x } 1 \\
N \text {-acetylcysteine 600mg, 1x1 } \\
\text { Amphotericin B Suspension, } \\
3 \mathrm{x} / \mathrm{d} \\
\text { Analgesics when required }\end{array}$ \\
\hline
\end{tabular}

\section{Case Reports:}

(I) A male patient, born 1957, with esophageal cancer was presented after neo-adjuvant radio-chemotherapy and achalasia, and with a history of myasthenia gravis. After esophageal resection, he was treated with ropivacaine $0,375 \%, 8 \mathrm{ml} / \mathrm{h}$ via an epidural catheter for a total of five days. On the first post-operative day he was satisfied with this treatment.

On post-operative day two, an additional infusion with i.v. morphine $(20 \mathrm{mg} / 24 \mathrm{~h})$ was added, reducing the pain level to numerical rating scale (NRS) 1.

On the forth post-operative day, the continuous morphine infusion was stopped and changed to subcutaneous morphine. The epidural was discontinued on day six and the patient received morphine $60 \mathrm{mg}$ every $8 \mathrm{~h}$ (the cumulative daily dose of the infusion plus $80 \mathrm{mg} / \mathrm{d}$ morphine, which the patient had already received prior to surgery), with the possibility of claiming
$10 \mathrm{mg}$ morphine up to ten times daily. However, this regimen resulted in steadily increasing levels of pain, and the ward staff became anxious. The epidural therapy was therefore restarted with ropivacaine $0.2 \%, 8 \mathrm{ml} / \mathrm{h}$. From noon onwards, the ward staff contacted the pain consultant every 15 minutes, as no sufficient pain reduction was observed.

A senior anesthesia attending examined the patient and administered a cumulative dose of $30 \mathrm{mg}$ morphine intravenously, which resulted in sufficient pain control. However, pain reduction lasted only until next morning. Therefore, a specialized pain therapist visited the patient, after discussing the case with a psychiatrist in the pain clinic.

The patient history and psychiatric evaluation revealed no thought disorder or disarray in perception or concentration. Yet the patient was angry, irritable and verbally aggressive concerning the unsuccessful pain therapy. The tumor surgery in combination with pain acted as an amplifier to the delusional certainty of "pain as punishment" for past misconduct. Yet the patient could follow questioning and understood the suggestions of the pain therapist.

The patient's history also revealed that he did not only use long-acting morphine prior to surgery but also that he was in psychiatric care for psychotic conditions. According to the patient, he was treated for delusional depression and had taken a strong neuroleptic prior to hospital admission (quetiapine 50 $0-150 \mathrm{mg}$ ). This medication was now augmented with a higher dose of quetiapine (50 - 0 - $250 \mathrm{mg}$ ). In addition, lorazepam (3 x $1 \mathrm{mg}$ ) was prescribed.

The patient was informed about the change of the therapeutic regimen, and the relation to his unsatisfactory pain management was discussed. Under the new medication, no exacerbations of pain occurred.

(II) A male patient, born 1990, with lymphatic metastases of a hereditary colon carcinoma, was presented to the pain consultant by the surgical team after right-sided hemicolectomy and splenectomy, currently under chemotherapy.

A few days prior, the patient was treated in the pain department by request from the surgical team. At this first contact, the up until then opioid-naïve patient received tilidine, $3 \mathrm{x}$ $50 \mathrm{mg} / \mathrm{d}$. This regimen had to be augmented to $3 \times 100 \mathrm{mg} / \mathrm{d}$, for the reason of increasing pain within the next few days. Later the patient was emergently admitted to the hospital with massive pain $(\mathrm{NRS}=10)$. Piritramide, $7.5 \mathrm{mg}$ (a synthetic opioid of 0.66 morphine equivalent $=5 \mathrm{mg}$ morphine), administered subcutaneously was sufficient to reduce pain to NRS 2 .

When the patient was presented as an inpatient to the pain consultant, the tilidine dose was increased to $3 \times 150 \mathrm{mg}$ per day and, additionally, lorazepam $3 \times 0.5 \mathrm{mg} / \mathrm{d}$ was prescribed.

During the following night the pain increased again. The patient's relatives voiced accusations against the resident physician because of this. The case was conveyed to the pain service. The repeated, now stat pain consult, looked at possibilities of an efficient and effective, meaning continuing, pain reduction and discussed the possible background relating to the pain: The patient is a single child; the parents have feelings of guilt arising from the hereditary nature of the tumor; extensive fears because the patient may die at young age before the parents. The patient prior to admission voiced these fears but they increased parallel to the pain during the hospital stay.

During the following night, pain increased again, which 
led to a further application of $7.5 \mathrm{mg}$ piritramide subcutaneously. Only the additional prescription of the neuroleptic risperidone $(2 \times 0.5 \mathrm{mg} / \mathrm{d})$ in addition to $3 \times 0.5 \mathrm{mg}$ of lorazepam resulted in a substantial pain reduction. Since then the patient complained of no pain.

\section{Discussion}

Especially from a surgical point of view, the interdisciplinary approach is frequently emphasized ${ }^{[6]}$. One can often find this philosophy lived on a daily basis, as particularly surgical colleagues often adhere to interdisciplinary consensus and actively implement decisions.

This can be demonstrated not least in a consultant service, for example at the University Hospital Magdeburg, where pain clinic has elementary traits of a liaison service, as physicians and nursing staff of the respective ward are included by the consultant in finding therapy options and in finding final decisions. This is aided by the, often repeated, presence of the pain consultant until the patient is satisfied with pain management. The surgeons allow the consultant liberty to treat these specific patients. This proven collaboration has an interdisciplinary goal of rapidly and efficiently setting pain medication in the perioperative and interventional course of every single patient, latest up until the day of discharge.

It is widely accepted that pain manifestations cannot be regarded outside of the patient history including current comorbidities, current phase of treatment (for example perioperative/-interventional), or the individual medication profile. In both presented cases aggressive behavior occurred due to dissatisfaction regarding attained therapy (concerning pain reduction). In review, the reason for the aggressive behavior was found in psychiatric comorbidities. However, there is only one newer study regarding aggression, mental pain, communication and suicidal tendency; but this addresses self-aggression in psychiatric patients and not hostility in surgical patients ${ }^{[7]}$.

In the first case the patient's psychoses was already established and exacerbated because of growing pain. An increase in dosing of the neuroleptic and additional prescription of lorazepam relieved the situation for the patient within a day.

For this reason, the relationship towards the different parties (nurses, surgical team, and anesthesia team) also improved. The experience, that an exacerbated psychosis can increase pain to the level where opioids in excess of $500 \mathrm{mg}$ morphine are insufficient, is one we have met previously ${ }^{[1]}$. The bottom line is that an increased dose of the neuroleptic plus additional benzodiazepine exerts a better effect on treating the pain than increasing the opioids alone. The reason can be found in treating the psychosis and with that the fears of the patient.

In the second case, an excessive history and psychiatric exploration was done in the pain clinic prior to the patient's admittance. A pre-existing psychosis was not found. Despite this, the patient was also treated with a highly potent neuroleptic and a benzodiazepine. Likewise, this resulted not only in a reduced level of pain for the patient but also deescalated the tense situation on the ward within some hours.

There are limitations in efficacy of pain therapy, such as insufficient dosage, preexisting opioid abuse, incompliance, and severe somatic disorders. However, sufficient administration of morphine in case 1 and of tilidine/piritramide in case 2 did not result in an adequate reduction of pain in both patients. The fact that under $3 \times 150 \mathrm{mg}$ tilidine the pain level reached NRS 10 , but $7.5 \mathrm{mg}$ of subcutaneous piritramide, the equivalent of $5 \mathrm{mg}$ of morphine $=50 \mathrm{mg}$ tilidine, reduced the pain level to NRS 2, points to a significant psychiatric component. Of great interest was the observation that a 30-minute conversation with the patient had the same effect on pain reduction.

During the first outpatient contact the suspicion arose that the parents of the patient had strong feelings of guilt due to the hereditary tumor, and that they did not know how to deal with the imminent death of their son. This situation made them prone for quick assignments of guilt against third parties. One can contemplate that what was seen here is what the Scandinavian literature calls a "Reactive Psychosis" ${ }^{[8]}$. It follows the assumption that an incident (tumor plus pain) only has to build up enough psychotic pressure, resulting in psychosis-like symptoms in a patient. That this happened with the patient cannot be surely proven but can be assumed due to the positive reaction to the highly potent neuroleptic agent.

Both cases presented here are of patients with a tumor, which we don't see as a coincidence. It can be assumed that the neoplasms act as an amplifier for pain and exacerbation of psychosis $^{[1]}$. Through their tendency for deterioration, they pose a very specific and therapeutically exploitable trigger of aggression.

Interestingly, the cause of aggression was also different in both cases. In the first, the aggression arose on basis of a delusional depression and the certainty that the current tumor is a punishment for past misconduct. In the second case, aggression occurred out of overpowering despair and the fear of imminent death. This spectrum of reasons for aggression poses a connection between the psychopathologic disease pole and the biological therapy pole.

It can be assumed that aggression is a reactive behavior towards fury and despair ${ }^{[9]}$, and despair can be alleviated or augmented through support given or denied by the family or the ward staff and therefore poses an important factor in the reduction of aggression ${ }^{[2]}$.

In addition, a dysfunction of the endogenic opioid system is hypothesized as a mechanism of aggression ${ }^{[10]}$. The chemical relationship between neuroleptics and opioids is well established, and is the reason that both of them can influence pain as well as fear and fury ${ }^{[11]}$.

\section{Summary}

To our knowledge, there are no reports of patients suffering from pain, depression and exhibiting a high level of verbal aggression. This combination requires a team of anesthesiologists specialized in pain therapy as well as psychiatry expertise. So from our point of view and drawing from past experience with manifest aggression in pain patients like those in the presented cases, the following algorithm can be proposed as a basis for future effective patient management and efficient communication between interdisciplinary teams [i.e. surgery and pain therapy/anesthesiology] as well as patients and relatives.

If a patient suffers from severe pain, which is unsusceptible to increased oral opioid dosing, at first an i.v. titration with an opioid should be attempted. Psychotropic drugs should be considered in the special case of psychosis with severe hostility. However, a missing response to painkillers often leads to 
aggressive behavior. Aside from the prescription of lorazepam, the prescription of a highly potent neuroleptic [i.e. $2 \times 0.5 \mathrm{mg}$ risperidone] is always indicated.

\section{References}

1. Brinkers, M., Pfau, G., Voigt, A., et al. [Pain therapy in patients with schizoaffective disorder and cancer]. (2015) Schmerz 29(2): 217-222.

2. Margari, F., Lorusso, M., Matera, E., et al. Aggression, impulsivity, and suicide risk in benign chronic pain patients - a cross-sectional study. (2014) Neuropsychiatr Dis Treat 10: 1613-1620.

3. Corbett, A., Burns, A., Ballard, C. Don't use antipsychotics routinely to treat agitation and aggression in people with dementia. (2014) BMJ 349: g6420.

4. Willner, P. The neurobiology of aggression: implications for the pharmacotherapy of aggressive challenging behaviour by people with intellectual disabilities. (2015) J Intellect Disabil Res 59(1): 82-92.

5. Volavka, J., Czobor, P., Citrome, L., et al. Effectiveness of antipsychotic drugs against hostility in patients with schizophrenia in the Clinical Antipsychotic Trials of Intervention Effectiveness (CATIE) study - ADDENDUM. (2014) CNS Spectr 19(5): 466.
6. Neugebauer, E. [Perspectives of surgical research 2020--a critical analysis and request for action in a changing research landscape]. (2013) Zentralbl Chir 138(2): 157-163.

7. Gvion, Y., Horresh, N., Levi-Belz, Y., et al. Aggression-impulsivity, mental pain, and communication difficulties in medically serious and medically non-serious suicide attempters. (2014) Compr Psychiatry 55(1): 40-50.

8. Stromgren, E. The development of the concept of reactive psychoses. (1989) Br J Psychiatry Suppl (4): 47-50.

9. Taft, C., Schwartz, S., Liebschutz, J.M. Intimate partner aggression perpetration in primary care chronic pain patients. (2010) Violence Vict 25(5): 649-661.

10. Bruehl, S., Burns, J.W., Chung, O.Y., et al. Pain-related effects of trait anger expression: neural substrates and the role of endogenous opioid mechanisms. (2009) Neurosci Biobehav Rev 33(3): 475-491.

11. Brinkers, M., Petz, T., Hoffmeyer, D. [Psychotropic drugs The special importance of anticonvulsants and neuroleptics in treatment of patients with chronic pain]. (2011) Anasthesiol Intensivmed Notfallmed Schmerzther 46(1): 20-27. 